\title{
Removal of fat from crushed black soldier fly larvae by carbon dioxide supercritical extraction
}

2007; Rumpold and Schlüter, 2013a; Spranghers et al., 2017). Since fish feed costs comprise $40-70 \%$ of the price of artificially grown fish, an increase in the price of feed directly affects their production cost (van Huis et al., 2013). Although protein-rich soybeans and other crops have been considered as alternative raw materials for fish feed, their use has been limited by the potential risk of digestive tract
Steady decline in wild fish catches and the increased use of fish meal in feeds intended for livestock and aquaculture led to an explosive increase in the prices of fish meal and fish oil (Verkerk et al.,

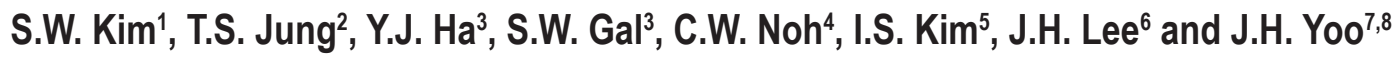 \\ ${ }^{1}$ Gene Analysis Center, Gyeongnam National University of Science and Technology, \\ 33 Dongjin-ro, Jinju-city 52725, South Korea \\ ${ }^{2}$ Laboratory of Aquatic Animal Diseases, College of Veterinary Medicine, Gyeongsang National University, \\ 501 Jinju-daero, Jinju-city 52828 , South Korea \\ ${ }^{3}$ Department of Pharmaceutical Engineering, Gyeongnam National University of Science and Technology, \\ 33 Dongjin-ro, Jinju-city 52725 , South Korea \\ ${ }^{4}$ Gyeongsangnam-do Agricultural Research and Extension Services, 570 Daesin-ro, Jinju-city, 52733, South Korea \\ ${ }^{5}$ Swine Science and Technology Center, Gyeongnam National University of Science \& Technology, \\ 33 Dongjin-ro, Jinju-city 52725 , South Korea \\ ${ }^{6}$ Inland Aquaculture Research Center, National Institute of Fisheries Science, 645-806 Gyeongnam, South Korea \\ ${ }^{7}$ Korea Aquatic Life Institute Co.Ltd, Geumjeong-ro 90, Geumjeong-ku, Busan-city 46290, South Korea
}

KEY WORDS: Hermetia illucens, feeds, particle size, pressure, processing, extraction, fat

Received: $\quad 16$ June 2018

Revised: 9 September 2018

Accepted: 19 March 2019

${ }^{8}$ Corresponding author:

e-mail: jhytomal@gmail.com

\begin{abstract}
The larvae of the black soldier fly, Hermetia illucens, contain high amounts of protein and fat, and so are a good feed source. However, this high fat content hinders the production of such feed. The excess fat must thus be removed to enable the larvae to be used as a feedstock e.g., for aquaculture and livestock. Firstly, the use of hot water treatment as a strategy for extracting fat from dried larvae was tested. It was found that this process reduced the fat content of the raw material (from 30 to about 16\%). However, the resulting product was still not suitable for feed processing. Next, the use of a carbon dioxide supercritical extraction system on crushed larvae was studied. This system time-dependently reduced the fat content to less than $6.6 \%$ and less than $4.6 \%$ after treatments for 2 and $6 \mathrm{~h}$, respectively, with a pressure of 350 bar used on larval particles of 10-18 mesh in size. Therefore, subjecting 10-18 mesh crushed larval powder to carbon dioxide supercritical extraction at 350 bar for $6 \mathrm{~h}$ yielded a larval powder with a fat content of $5 \%$ or less. Based on this finding, this method is proposed to be a suitable alternative for further processing of larvae feedstock.
\end{abstract}

\section{Introduction}


inflammation (Bravo-Tello et al., 2017; Gu et al., 2017; Perera and Yúfera, 2017).

Most aquacultured fishes need animal protein, and the production of fish feed requires more and higher-quality fishmeal in comparison to the production of livestock feed. As recent increases in the price of fishmeal have boosted the operating costs of fish farmers, efforts are underway to identify alternative protein sources. One potential option is the use of insects. This could be the most economical option, since insects mostly feed on food waste and livestock manure (Čičková et al., 2015). Insect larvae contain large amounts of protein, unsaturated fatty acids and minerals that can be ingested and digested by farmed fishes (Rumpold and Schlüter, 2013a; Rothman et al., 2014; Nowak et al., 2016; Spranghers et al., 2017). To date, however, the production of insect larvabased fish feeds has been hindered by cost issues and problems with the production pipeline. If we hope to further develop insect larva-based feeds for aquaculture, we must identify insects that can be reared easily at a very large scale for a small cost.

The adult, pupal and larval forms of insects have protein contents that range widely from 37 to $76 \%$. Since about $50 \%$ of their dry weight is composed of proteins, they are considered to be valuable protein sources (Rothman et al., 2014). The fat content of insects is about $30-40 \%$, the saturated-to-unsaturated fatty acid ratio is about 0.5 , and the main unsaturated fat has a high proportion of oleic acid and alpha-linolenic acid. These fatty components add to the potential value of insects as functional feed materials (Rumpold and Schlüter, 2013b). However, this high fatty acid content is difficult to be pulverized due to the oil component when the powder is induced for use as a feed source. Therefore, it is essential to optimize the amount of fat in insect preparations to enable an efficient feed-mixing process.

In order to reduce the oil residues in powdered black soldier larvae, two extraction methods were compared: hot water and carbon dioxide supercritical. The latter process was found to yield a powder with less than $5 \%$ larval oil, which could be utilized for further feed processing.

\section{Material and methods}

\section{Sources of black soldier fly larvae and drying}

Fifth instar larvae of the black soldier fly (Hermetia illucens) were purchased from Jiri Mountain Insect Research Institute company (San Cheong county, South Korea), and reared at $25 \sim 30{ }^{\circ} \mathrm{C}$, up to $60 \%$ humidity with 24 h dark cycle. Drying of the larvae (purchased in the amount of 1 ton) was done by microwave for 15 min (PRUNUS DRY, South Korea). The dried larvae were either directly used as samples for oil removal or stored at $4{ }^{\circ} \mathrm{C}$.

\section{Hot water extraction}

Black soldier fly larvae $(100 \mathrm{~g})$ were put in a 24-mesh net, mixed with water (9:1 water to larvae, $v / v$ ), and then heated at $121{ }^{\circ} \mathrm{C}$ for $15 \mathrm{~min}$. The water was removed, the larvae were dried at $60{ }^{\circ} \mathrm{C}$ for $24 \mathrm{~h}$, and the powder obtained by grinding the larvae was analyzed for its contents of crude protein, crude fat and ash. In order to reduce the variability resulting from the individual effects of the larvae, powders obtained from the extraction of three different samples were mixed.

\section{Carbon dioxide supercritical extraction}

Black soldier fly larvae were dried in a microwave dryer (PRUNUS DRY, Hwaseong-si, South Korea) and crushed with a pin mill pulverizer (DK201; Sejung Tech, Daegu, South Korea). The crushed larvae $(400 \mathrm{~g})$ were placed in a carbon dioxide supercritical vessel (SC-CO ${ }_{2}$ Gas Extraction System; Suflux, South Korea) and extracted for $2 \mathrm{~h}$ at $35{ }^{\circ} \mathrm{C}$ using pressures of 150,250 or 350 bars at a flow rate of $26 \mathrm{C} \mathrm{CO}_{2} / \mathrm{h}$. To examine fat extraction according to particle size, the particles into groups of up to 5 mesh, 5-10 mesh, 11-18 mesh and over 18 mesh were sorted, and fat extraction for $2 \mathrm{~h}$ at $35^{\circ} \mathrm{C}$ with a pressure of 350 bar and a flow rate of $261 \mathrm{CO}_{2} / \mathrm{h}$ was performed. To examine extraction over time, 11-18 mesh samples were extracted for 2,4 , and $6 \mathrm{~h}$ with a pressure of 350 bar and a flow rate of $261 \mathrm{CO}_{2} / \mathrm{h}$. Like in the hot water extraction powders obtained from the extraction of three different samples were mixed. All extracted fatty acids (extracts) and post-extraction residue (i.e. the fat-extracted powders) were analyzed for their fatty acid and general chemical compositions.

\section{Analysis of general nutrition components}

The post-extraction powders of larvae were pulverized at $4600 \mathrm{rpm}$ with a pin mill pulverizer (DK201; Sejung Tech, Daegu, South Korea) and then analyzed for general nutrition components as described by the Association of Official Agricultural Chemists (AOAC International, 2016). Briefly, the crude fat content was analyzed by the Soxhlet method, the ash content was measured by the muffle furnace method at $550{ }^{\circ} \mathrm{C}$, and the crude protein content was quantitatively analyzed using 
a 2300 Kjeldahl Analyzer Unit (Foss Tecator, Eden Prairie, MN, USA). Inorganic components (calcium, magnesium, natrium phosphate, and potassium) were measured using the previously described dry method (NAAS, 2010). Briefly, $1 \mathrm{~g}$ of sample was burned in the muffle furnace and the ash was mixed with $50 \mathrm{ml}$ of $0.5 \mathrm{~N} \mathrm{HNO}_{3}$ and filtered with a GF/C filter $(90 \mathrm{~mm}$, Cat No. 1822 090; Whatman International Ltd., Maidstone, UK). The filtrate was adjusted to $50 \mathrm{ml}$ with $0.5 \mathrm{~N} \mathrm{HNO}_{3}$ and analyzed using an inductively coupled plasma spectrometer (ICP; Thermo Jarrell Ash, Franklin, MA, USA).

\section{Analysis of fatty acids}

The extracted crude fat of the pooled samples $(0.5 \mathrm{~g})$ was mixed with $2 \mathrm{ml}$ of reaction reagent containing methanol:heptane:benzene:2,2dimethoxypropane: $\mathrm{H}_{2} \mathrm{SO}_{4}(37: 36: 20: 5: 2, \mathrm{v} / \mathrm{v})$ and reacted for $20 \mathrm{~min}$ at $80{ }^{\circ} \mathrm{C}$. The supernatant of the reacted solution was concentrated by nitrogen, dissolved in hexane and analyzed for fatty acids as previously described (Lee and Kye, 1970) using gas chromatography (Agilent 6850 GC; Agilent Technologies, Wilmington, NC, USA) with an HPINNOWAX column $(30 \mathrm{~m} \times 0.25 \mathrm{~mm}, 0.25 \mu \mathrm{m}$; Agilent Technologies, Wilmington, NC, USA) and a flame ionization detector. The applied inlet and detector temperatures were set at $250{ }^{\circ} \mathrm{C}$ and $300{ }^{\circ} \mathrm{C}$, respectively. The oven temperature was held for 5 min at $120{ }^{\circ} \mathrm{C}$, raised by $5{ }^{\circ} \mathrm{C}$ per min until it reached $230{ }^{\circ} \mathrm{C}$ and then maintained for $5 \mathrm{~min}$ at $230{ }^{\circ} \mathrm{C}$. The utilized carrier gas was $\mathrm{N}_{2}(99.999 \%)$ and the flow rate was injected by $1.3 \mathrm{ml} / \mathrm{min}$ until finally $1 \mu$. The fatty acid composition is presented as the relative ratios of the peak areas.

\section{Statistical analysis}

The collected data were analyzed using the PROC ANOVA procedure of the SAS program (ver. 9.2; SAS Institute Inc, Cary, NC, USA). Mean values that differed at the level of 5\% significance were verified using Duncan's multiple range test (DMRT).

\section{Results and discussion}

\section{Extraction of fat by hot water}

Since black soldier fly, Hermetia illucens, larvae have crude protein, fat and fiber contents of 42.1, 34.8 and $7.0 \%$, respectively, these larvae have been studied as a feed sources for aquaculture and livestock (Čičková et al., 2015; Józefiak et al., 2018).
However, the processing of black soldier fly larvae into a feed source is hindered by the excessive fat content, which obstructs the pulverization process. Here, the abilities of hot water extraction and carbon dioxide supercritical extraction to remove the excess oil from the larval powder were tested and compared.

For hot water extraction, dried larvae were placed in a 24-mesh net and heated at $121{ }^{\circ} \mathrm{C}$ for $15 \mathrm{~min}$. Subsequent analyses revealed that the yield, moisture content, fat content and ash content of the end product were $25,7.42,15.97$ and $13.26 \%$, respectively (Table 1). The resulting product of fat extraction by hot water from $0.5 \mathrm{t}$ of the dried larvae was adjusted into a proper amount of fat content, but due to the remained fat content in the larvae, processing could not be formulated into a feedstock. Thus, it was suggested that it is best to maintain a fat content of less than $10 \%$ for the proper processing of the feed.

Table 1. Chemical composition of dried black soldier fly (Hermetia illucens) larvae before extraction and post-extraction residue obtained after hot water extraction

\begin{tabular}{lll}
\hline Indices & $\begin{array}{l}\text { Dried larvae } \\
\text { before extraction }\end{array}$ & $\begin{array}{l}\text { Post-extraction } \\
\text { residue }\end{array}$ \\
\hline Yield, \% & - & 25 \\
Moisture, \% & 7.02 & 7.42 \\
Crude fat, \% & 32.5 & 15.97 \\
Ash, \% & 11.03 & 13.26 \\
\hline
\end{tabular}

\section{Removal of larval fat by carbon dioxide supercritical extraction under different pressure conditions}

Carbon dioxide supercritical extraction has been widely used to extract essential oils from plants. Recently, the system has been used to extract oil from oak silkworm (Antheraea pernyi) and mealworm (Tenebrio molitor) larvae, and such extractions have exhibited very high yields (Pan et al., 2012; Purschke et al., 2017). Since we were unable to extract fat sufficiently by using hot water, as described above, the use of carbon dioxide supercritical extraction under different pressure conditions was then examined. The extraction yield increased with pressure, from $16 \%$ at 150 bar to $24.5 \%$ at 350 bar. As the pressure increased, the amount of fat gradually decreased in the postextraction residue (Figure 1A). Similar tendencies were observed in the previous studies on insect larvae such as oak silkworm and mealworm (Pan et al., 2012; Purschke et al., 2017). The contents of all examined minerals in the post-extraction powders 
A

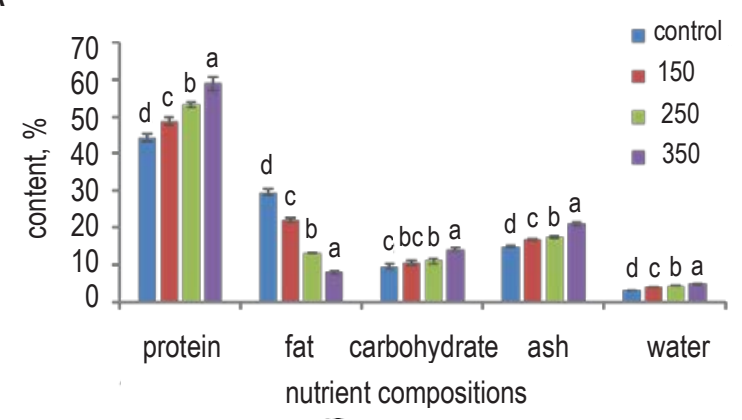

B

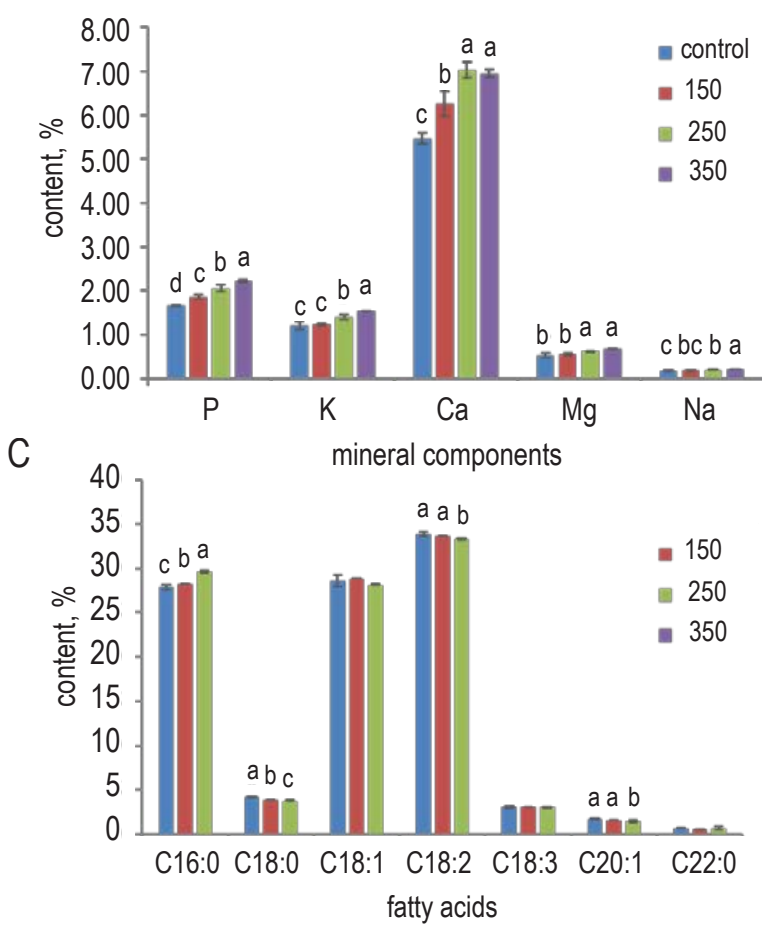

Figure 1. Pressure-associated changes in (A) nutrient compositions, (B) mineral components of post-extraction residue and (C) fatty acid profile of extracts obtained from crushed black soldier fly (Hermetia illucens) larvae using carbon dioxide supercritical extraction

Control - dried larvae before extraction (A and B); Each component was analyzed by triple technical repeats independently; Bars with different letters within each examined component differ significantly at $P<0.05$; C16:0 - palmitic acid; C18:0 - stearic acid; C18:1 - oleic acid (n-9); C18:2 - linoleic acid (n-6); C18:3 - linolenic acid (n-3); C20:0 - arachidic acid; and C22:0 - docosanoic acid

increased with increasing pressure (Figure 1B). Pressure was found to have little effect on the fatty acid composition of extracts (Figure 1C); palmitic acid (C16:0) showed the greatest difference in this regard, but this difference was less than $2 \%$. For all pressure conditions, the unsaturated fatty acid content of the extract was approximately twice the saturated fatty acid content (66.8 and 33.2\%, respectively). The most common fatty acids in the extract were linoleic acid (C18:2, n-6 family; $33.6 \%)$, followed by oleic acid (C18:1, n-9 family;
28.6\%) and palmitic acid (C16:0, saturated; 28.6\%). Conversely, alpha-linolenic acid (C18:3, n-3 family), paullinic acid (C20:1, n-7 family), stearic acid (C18:0, saturated) and arachidic acid (C20:0, saturated) were detected at low concentrations.

Taken together, as a result of fat extraction with pressure, the extraction process is most sufficient using pressure at 350 bar.

\section{Carbon dioxide supercritical extraction- based removal of fat from larvae representing different particle-size groups}

To examine the effect of the larval particle size on extraction, we used a pressure of 350 bar (based on the above results) for $2 \mathrm{~h}$ (to reduce cost) at a temperature of $35^{\circ} \mathrm{C}$ and a flow rate of $261 \mathrm{CO}_{2} / \mathrm{h}$. The extraction yield was very low for the up to 5 mesh group $(0.59 \%)$, increased to $8-8.5 \%$ for the up to 10 mesh group, increased further to $41.12-48.16 \%$ for the 5-18 mesh group, and then decreased somewhat to $34.51 \%$ for the over 18 mesh group (Figure $2 \mathrm{~A}$ ). We speculate that the yield of the latter group might have decreased because the smaller particles are removed (washed) by the movement of the extracting solvent. Based on our results, since the extraction yield and protein content using 10-18 mesh particles showed highest value, we selected 10-18 mesh particles for the next experiment. Our analysis of nutritional components revealed that protein, $\mathrm{K}, \mathrm{Mg}$ and $\mathrm{Na}$ contents in post-extraction residues increased in inverse proportion to the fat content (Figure 2A and B). These findings together suggest that our extraction method is appropriate for removing excess fat from the powdered larvae.

The fatty acid composition of the extract was found to differ by particle size. The extracted amount of palmitic acid (C16:0) was inversely proportional to the particle size, whereas those of oleic acid (C18:1, n-9 family) and linoleic acid (C18:2, n-6 family) was proportional (Figure 2C). The extraction yields significantly decreased with increasing particle size for oleic acid and linoleic acid, but increased with particle size for palmitic acid (Figure 2C). Notably, saturated fatty acids with low fluidity tended to show enhanced extraction as the particle size decreased. Thus the use of a particle size of 10-18 mesh would enable the removal of more saturated fatty acids, and thus could be more appropriate for feedstock production.

\section{Removal of larval fat by carbon dioxide supercritical extraction of different durations}

Finally, we set the conditions to a pressure of 350 bar, a temperature of $35^{\circ} \mathrm{C}$, a particle size of 

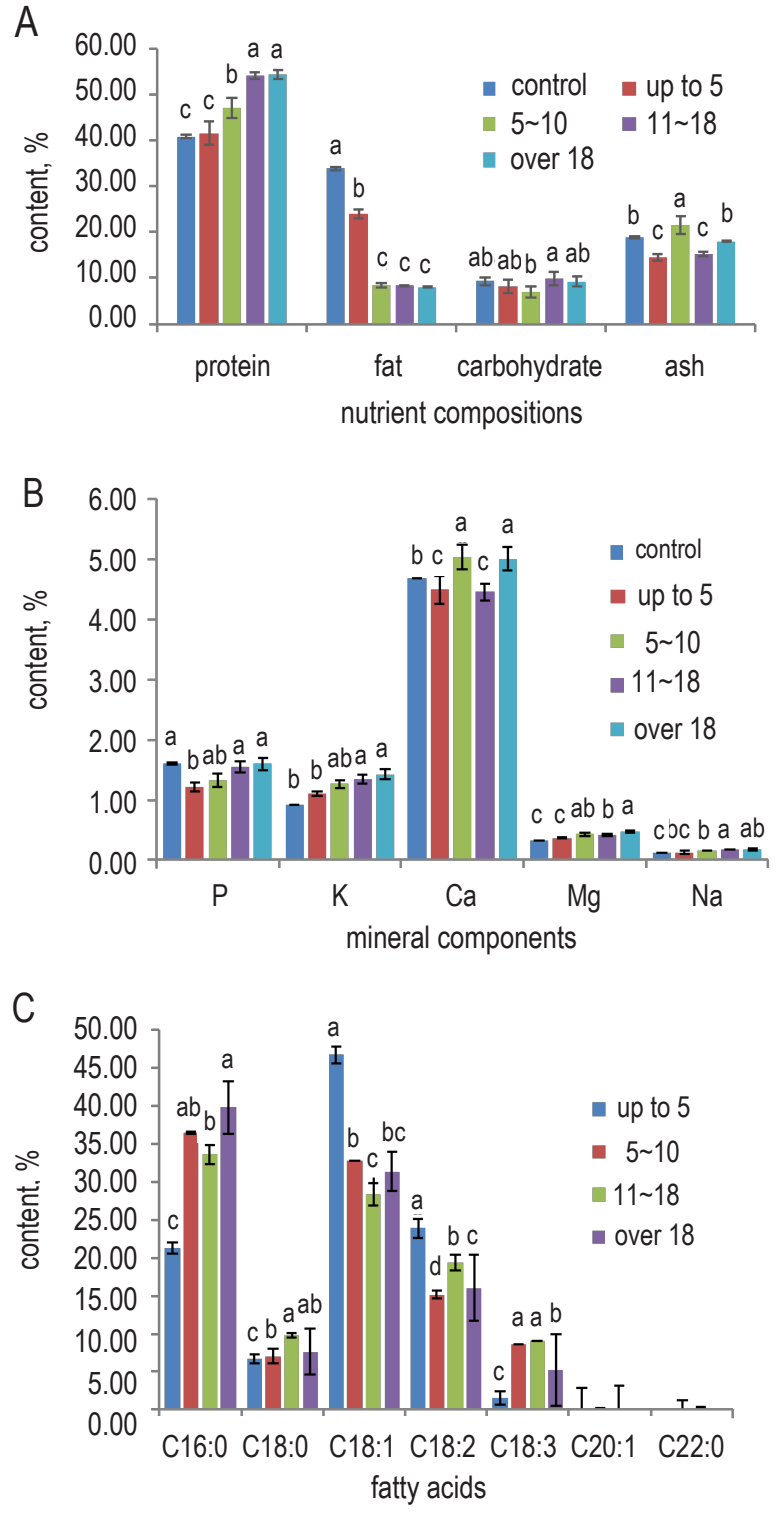

Figure 2. Particle size-associated differences in the $(A)$ nutrient compositions and (B) mineral components of post-extraction residue and $(C)$ fatty acid profile of extracts obtained from crushed black soldier fly (Hermetia illucens) larvae using carbon dioxide supercritical extraction

Control - dried larvae before extraction (A and B); Each component was analyzed by triple technical repeats independently; Bars with different letters within each examined component differ significantly at $P<0.05$; C16:0 - palmitic acid; C18:0 - stearic acid; C18:1 - oleic acid (n-9); C18:2 - linoleic acid (n-6); C18:3 - linolenic acid (n-3); C20:0 - arachidic acid; and C22:0 - docosanoic acid

10-18 mesh and a flow rate of $261 \mathrm{CO}_{2} / \mathrm{h}$, and then obtained the results from 2, 4 and $6 \mathrm{~h}$ of extraction. The fat content in the extracted powder ranged from $4.58 \%$ at $6 \mathrm{~h}$ to $7.01 \%$ at $4 \mathrm{~h}$ (Figure $3 \mathrm{~A}$ ). The extraction yield increased with time from 32 to $36 \%$; this difference was not significant, but increasing the extraction time appeared to have a positive effect on the yield. These results are consistent with those of the previous studies using mealworm and
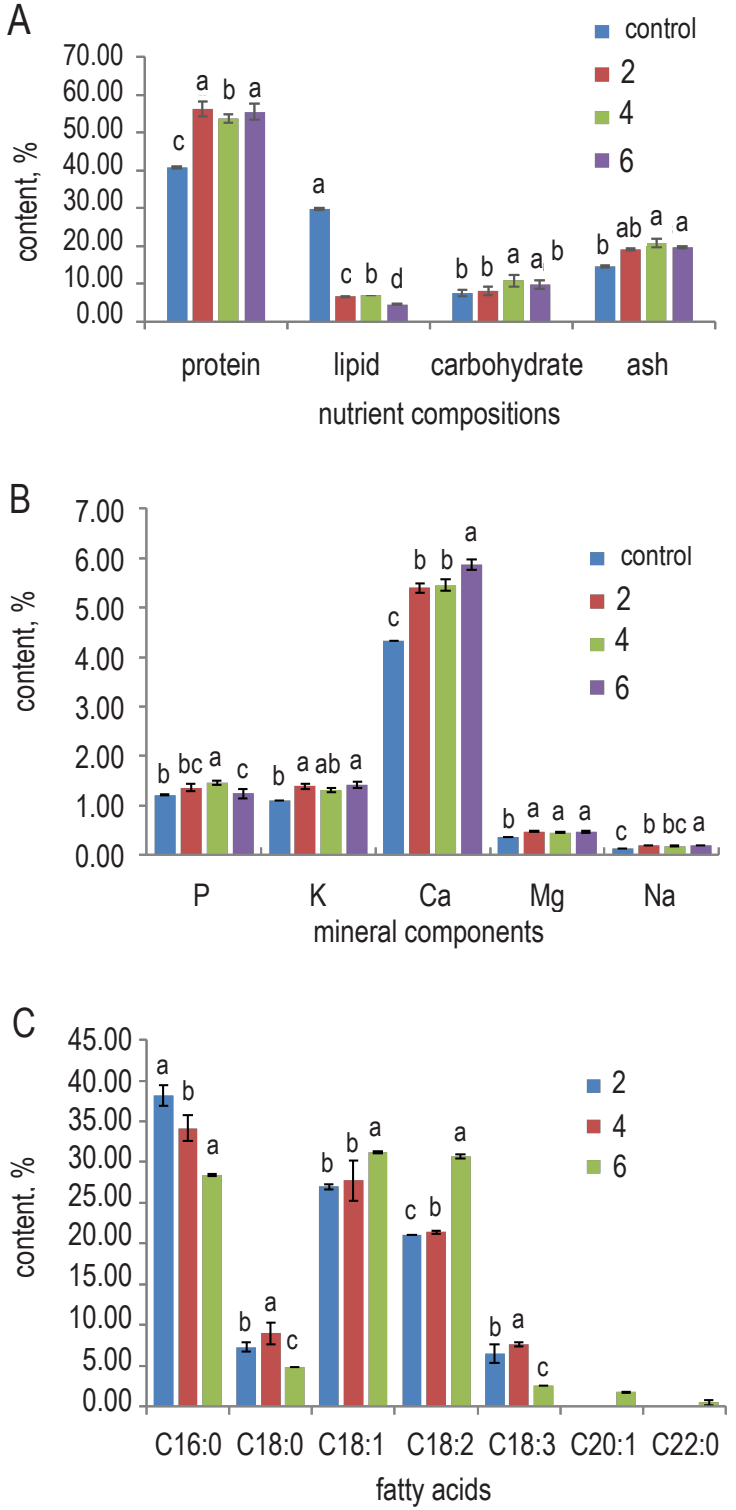

Figure 3. Time-dependent (2, 4 and 6 h) differences in (A) nutrient compositions and (B) mineral components of post-extraction residue and $(C)$ fatty acid profile of extracts obtained from crushed black soldier fly (Hermetia illucens) larvae using carbon dioxide supercritical extraction

Control - dried larvae before extraction (A and B); Each component was analyzed by triple technical repeats independently; Bars with different letters within each examined component differ significantly at $P<$ 0.05; C16:0 - palmitic acid; C18:0 - stearic acid; C18:1 - oleic acid (n-9); C18:2 - linoleic acid (n-6); C18:3 - linolenic acid (n-3) C20:0 - arachidic acid; and C22:0 - docosanoic acid

oak silkworm larvae (Pan et al., 2012; Purschke et al., 2017). Notably, the post-extraction powder had a fat content of less than 5\% when it was extracted for $6 \mathrm{~h}$ (Figure 3A). The protein and carbohydrate contents were inversely increased with the duration of fat extraction (Figure 3A). $\mathrm{Ca}$ and $\mathrm{Na}$ contents in the inorganic components were increased after $6 \mathrm{~h}$ extraction in comparison to 2 and $4 \mathrm{~h}$ ones, whereas $\mathrm{P}$ content was decreased after $6 \mathrm{~h}$ in comparison to 
other times (Figure 3B). For the fatty acid components in extracts, the extracted amount of palmitic acid (C16:0) was inversely proportional to the extraction time, that of oleic acid (C18:1) and linoleic acid (C18:2) showed similar levels at 2 and $4 \mathrm{~h}$, but showed a sharp increase at $6 \mathrm{~h}$. Stearic acid (C18:0) and alpha-linolenic acid (C18:3) showed the lowest values in after $6 \mathrm{~h}$ extraction (Figure 3C).

\section{Conclusions}

Since black soldier fly, Hermetia illucens, larvae contain high oil contents, which hinders the feed process, we succeeded in removing the oil through carbon dioxide supercritical extraction. The fat content in powdered black soldier fly larvae could be optimized by applying supercritical carbon dioxide extraction performed at 350 bar for $6 \mathrm{~h}$, using a particle size of 10-18 mesh, a temperature of $35{ }^{\circ} \mathrm{C}$ and a flow rate of $261 \mathrm{CO}_{2} / \mathrm{h}$. After such process, less than $5 \%$ of oil in the larval powder is present. In conclusion, this method proved highly effective feed production process with black soldier fly larvae.

\section{Acknowledgements}

This work was supported by a grant from the National Institute of Fisheries Science, Republic of Korea (R2019032), and by Priority Research Centers Program through the National Research Foundation of Korea (NRF) funded by the Ministry of Education (2009-0093813).

\section{References}

AOAC International, 2016. Official Methods of Analysis of AOAC International. $20^{\text {th }}$ Edition. Rockville, MD (USA)

Bravo-Tello K., Ehrenfeld N., Solís C.J., Ulloa P.E., Hedrera M., Pizarro-Guajardo M., Paredes-Sabja D., Feijóo C.G., 2017. Effect of microalgae on intestinal inflammation triggered by soybean meal and bacterial infection in zebrafish. PLoS One 12, e0187696, https://doi.org/10.1371/journal.pone.0187696

Čičková H., Newton G.L., Lacy R.C., Kozánek M., 2015. The use of fly larvae for organic waste treatment. Waste Manag. 35, 68-80, https://doi.org/10.1016/j.wasman.2014.09.026

Gu M., Bai N., Xu B., Xu X., Jia Q., Zhang Z., 2017. Protective effect of glutamine and arginine against soybean meal-induced enteritis in the juvenile turbot (Scophthalmus maximus). Fish Shellfish Immunol. 70, 95-105, https://doi.org/10.1016/j. fsi.2017.08.048
Józefiak A., Kierończyk B., Rawski M., Mazurkiewicz J., Benzertiha A., Gobbi P., Nogales-Merida S., Światkiewicz S., Józefiak D., 2018. Full-fat insect meals as feed additive - the effect on broiler chicken growth performance and gastrointestinal tract microbiota. J. Anim. Feed Sci. 27, 131-139, https://doi. org/10.22358/jafs/91967/2018

Lee J.I., Kye B.M., 1970. Effect of oil quality by extracting hour on rape. Res. Rept. RDA (C.P.) 13, 89-94

NAAS, 2010. Fertilizer Application Recommendations for Crop Plants. National Academy of Agricultural Science (NAAS), RDA, Suwon, Korea

Nowak V., Persijn D., Rittenschober D., Charrondiere U.R., 2016. Review of food composition data for edible insects. Food Chem. 193, 39-46, https://doi.org/10.1016/j.foodchem.2014.10.114

Pan W.J., Liao A.M., Zhang J.G., Dong Z., Wei Z.J., 2012. Supercritical carbon dioxide extraction of the oak silkworm (Antheraea pernyi) pupal oil: process optimization and composition determination. Int. J. Mol. Sci. 13, 2354-2367, https://doi. org/10.3390/ijms 13022354

Perera E., Yúfera M., 2017. Effects of soybean meal on digestive enzymes activity, expression of inflammation-related genes, and chromatin modifications in marine fish (Sparus aurata L.) larvae. Fish Physiol. Biochem. 43, 563-578, https://doi. org/10.1007/s10695-016-0310-7

Purschke B., Stegmann T., Schreiner M., Jäger H., 2017. Pilot-scale supercritical $\mathrm{CO}_{2}$ extraction of edible insect oil from Tenebrio molitor L. larvae - Influence of extraction conditions on kinetics, defatting performance and compositional properties. Eur. J. Lipid Sci. Technol. 119, 1-12, https://doi.org/10.1002/ ejt.201600134

Rothman J.M., Raubenheimer D., Bryer M.A., Takahashi M., Gilbert C.C., 2014. Nutritional contributions of insects to primate diets: Implications for primate evolution. J. Hum. Evol. 71, 59-69, https://doi.org/10.1016/j.jhevol.2014.02.016

Rumpold B.A., Schlüter O.K., 2013a. Potential and challenges of insects as an innovative source for food and feed production. Innov. Food Sci. Emerg. Technol. 17, 1-11, https://doi. org/10.1016/j.ifset.2012.11.005

Rumpold B.A., Schlüter O.K., 2013b. Nutritional composition and safety aspects of edible insects. Mol. Nutr. Food Res. 57, 802-823, https://doi.org/10.1002/mnfr.201200735

Spranghers T., Ottoboni M., Klootwijk C., Ovyn A., Deboosere S., De Meulenaer B., Michiels J., Eeckhout M., De Clercq P., De Smet S., 2017. Nutritional composition of black soldier fly (Hermetia illucens) prepupae reared on different organic waste substrates. J. Sci. Food Agric. 97, 2594-2600, https:// doi.org/10.1002/jsfa. 8081

van Huis A., Van Itterbeeck J., Klunder H., Mertens E., Halloran A., Muir G., Vantomme P., 2013. Edible Insects. Future prospects for food and feed security. FAO Forestry Paper 171, Rome (Italy), http://www.fao.org/docrep/018/i3253e/i3253e.pdf

Verkerk M.C., Tramper J., van Trijp J.C.M., Martens D.E., 2007. Insect cells for human food. Biotechnol. Adv. 25, 198-202, https:/l doi.org/10.1016/j.biotechadv.2006.11.004 